\title{
A BAT Optimization Algorithm for Sizing and Siting of Optimal Distributed Generation in Distribution Networks
}

\author{
Hamid Radmanesh $^{1} \quad$ Reza Sharifi $^{2} \quad$ Seyed Hamid Fathi $^{3}$ \\ ${ }^{1}$ Associate Professor, Electrical Engineering Department, Shahid Sattari Aeronautical University of Technology, Tehran, Iran \\ Radmanesh@ssau.ac.ir \\ ${ }^{2}$ Postdoctoral Researcher, Electrical Engineering Department, Amirkabir University of Technology, Tehran, Iran \\ Reza.sharifi@aut.ac.ir \\ ${ }^{3}$ Professor, Electrical Engineering Department, Amirkabir University of Technology, Tehran, Iran \\ fathi@aut.ac.ir
}

\begin{abstract}
:
The aim of this paper is to provide the best locations and sizes of DGs to aim voltage and power loss improvement with consider costs. The objective function in this paper is a multi-objective function with weights. The main functions are minimization of the power loss, improvement of voltage profile and minimization of DG cost are transformed into a single objective function with utilization the weight of functions. A BAT algorithm is proposed for simultaneous optimization these functions. Hence, in the first stage in this paper introduces the multi-objective function. Next stage is introduced the optimization algorithm used and in the last stage simulation results are presented. The proposed method has been tested on a 13-bus system. The results indicate that any change in the function's weight in the objective function leads to a significant change in the forecasting of the location and size of DG.
\end{abstract}

Keywords: DG, Size, Location, BAT Algorithm, Power Losses, Voltage Profile

Article Type: Research paper

Submission date : 20, Jan. 2020

Conditional Acceptance date: 28, June. 2020

Acceptance date : 15 , Nov. 2020

Corresponding author : R. Sharifi

Corresponding author's address: Electrical Engineering Department, Amirkabir University of Technology, Tehran, Iran 


\section{Introduction}

Distributed generation (DG) is small power generation technology that provides electric power at a site near to load center. The association of DG in power distribution networks has become important in the last decades.

These sources in power grid, compensated lack of power obtained from the original network by injected active and reactive power. So that by placed this equipment at network, the above problems can be better.

These resources have been installed in low voltage busses and also can improve voltage profile which leads to reduce the network losses. This method can overcome the cost of installation and maintenance of DG resources, in addition will brought profitability and relief to the financial problems. Also before installing DG resources, the power system design points such as sizing, location, type and number of DG until should be considered to have the highest returns of technically and financially.

Many paper in this issue have done so many different things and each of them have tried by using various optimization techniques, to examine various functions of the objective function and will be improved the network. Using the genetic algorithms to benefit from renewable energy sources to improve voltage profile and increase load ability rate [1-6]. The load flow analysis is done to specify the sensitive buses to voltage collapse, improved voltage profile and reduced power losses in the network [6-8]. Using Optimization Reactive Power Flow (ORPF) and immune algorithm in network have been improved the voltage stability [8]. Due to the different load models in distribution system and using placement and sizing of distribution generation sources, the power system losses should be minimized [9]. Using parallel Flexible AC Transmission System (FACTS) elements in the network and placement and sizing in distribution level, focused on improve load ability factor and improve voltage profile [1012]. Using voltage constraint, feeders capacity and DG sources level, based on placement and sizing has been improved the voltage stability in distribution system [10]. Using Particle Swarm Optimization (PSO) method and Genetic Algorithm (GA) method and comparison between results of theme, by focused on the optimal placement and sizing of distributed generation to reduce network losses and improved voltage profile has been presented in [14-17]. Increasing the injected amounts of DG power to the grid, focused on the network losses, system load ability factor and buses voltage constraints has been studied in [15]. Using DG and capacitor placement and sizing and comparisons between each of these components based on BPSO algorithm have been improved the voltage profile [16-25].

The remains of this paper are organized as follows: Section II provides mathematical model of the system and problem definition. Section III provides case studies, and BAT optimization algorithm is represented in Section IV. Section $\mathrm{V}$ provides simulation results and section $\mathrm{V}$ outlines conclusions.

\section{Problem Formulation}

In this paper, we use a multi-objective function with weights to find optimal location of DG. The multi-objective function that is use in this paper has three main function including voltage profile, network losses and DG costs. It is important to determine the weight of each of these functions on the DG placement and capacity. In order to obtain this aim, we have:

$$
\begin{aligned}
& \text { multi-objective function }= \\
& K_{1} P_{\mathrm{IOss}}+K_{2}\left|\left(\left(\mathrm{~V}-\mathrm{V}_{\mathrm{nom}}\right) / 0.05\right)^{2}\right|+\mathrm{K}_{3} \operatorname{COST}_{\mathrm{DG}}
\end{aligned}
$$

Where, $\mathrm{P}_{\text {loss }}$ represent the amount of losses and COSTDG related to DG fuel cost and $\mathrm{K} 1$ is weight factor of the losses reduction function, $\mathrm{K}_{2}$ is weight factor of the voltage profile function and $\mathrm{K}_{3}$ is weight factor of the fuel cost function and the weight of all factors are:

$\mathrm{K} 1+\mathrm{K} 2+\mathrm{K} 3=1$

Also, the normal value of the voltage range in each bus is between $0.95 \mathrm{pu}$ to $1.05 \mathrm{pu}$. Absolute value of the middle term represents the voltage deviation from the specified range.

In this paper, using BAT optimization algorithm can determine the weight of changing in each function on the DG placement and capacity.

\section{Distribution Network Modeling}

The studied distribution network is a distribution system with the total load of $10536 \mathrm{~kW}$ and 5992kVAR, 13 bus and 12 branches as it has been shown in Fig. 1.

Bus and line information of 13-bus test system are listed in Tables (1) and (2), respectively.

Table.1. Line Information

\begin{tabular}{|c|c|c|c|}
\hline From & To & $\mathrm{R}(\mathrm{ohm})$ & $\mathrm{X}(\mathrm{ohm})$ \\
\hline 1 & 2 & 0.176 & 0.138 \\
\hline 2 & 3 & 0.176 & 0.138 \\
\hline 3 & 4 & 0.045 & 0.035 \\
\hline 4 & 5 & 0.089 & 0.069 \\
\hline 5 & 6 & 0.045 & 0.035 \\
\hline 5 & 7 & 0.116 & 0.091 \\
\hline 7 & 8 & 0.073 & 0.073 \\
\hline 8 & 9 & 0.074 & 0.058 \\
\hline 8 & 10 & 0.093 & 0.093 \\
\hline 7 & 11 & 0.063 & 0.05 \\
\hline 11 & 12 & 0.068 & 0.053 \\
\hline 7 & 13 & 0.062 & 0.053 \\
\hline
\end{tabular}

Table.2. Bus information

\begin{tabular}{|c|c|c|}
\hline Bus Number & $\mathrm{P}(\mathrm{KW})$ & $\mathrm{Q}(\mathrm{KVAR})$ \\
\hline 1 & 0 & 0 \\
\hline 2 & 890 & 468 \\
\hline 3 & 628 & 470 \\
\hline 4 & 1112 & 764 \\
\hline 5 & 1638 & 1378 \\
\hline 6 & 474 & 344 \\
\hline 7 & 1342 & 1078 \\
\hline 8 & 920 & 292 \\
\hline 9 & 766 & 498 \\
\hline
\end{tabular}




\begin{tabular}{|c|c|c|}
\hline 10 & 1662 & 480 \\
\hline 11 & 690 & 186 \\
\hline 12 & 1292 & 554 \\
\hline 13 & 1124 & 1480 \\
\hline
\end{tabular}

This 13-bus test system $63 / 20 \mathrm{kV}$ has obtained from KhodaBande-Loo Substation of Tehran distributed network [26].

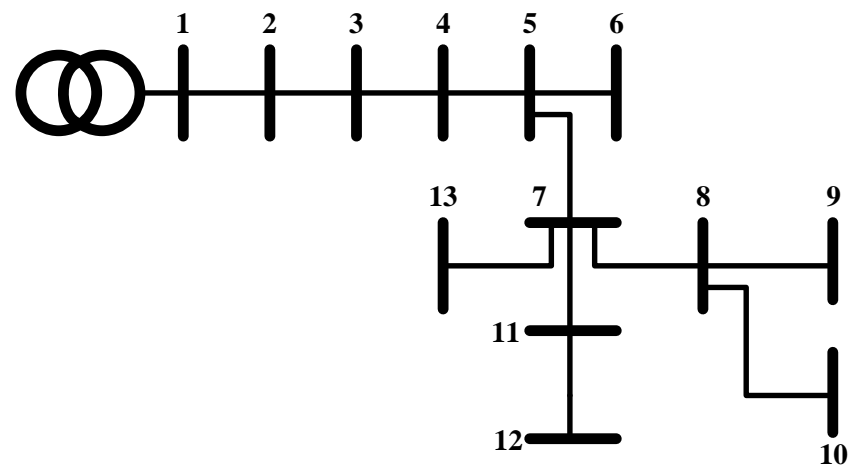

Fig. 1. Single line diagram of the case study system

\section{Proposed Algorithm}

BAT optimization algorithm is one of the optimization algorithms which can solve the problems that need to optimization [21-25]. This optimization algorithm is inspired by the life of BAT. Bat algorithm is among Heuristic an algorithm which is inspired from echolocation behavior of bats. Bats use this technique which is based on sending and receiving pulses with fast rates to detect obstacles and find their way in the dark [21-25]. In this optimization algorithm it is supposed that virtual bats are located at position (solution) $\mathrm{x}_{\mathrm{i}}$ and they fly with random velocities $V_{i}$ and send and receive variable wavelength, loudness and frequency f pulses to locate their objects. The position and velocity of these virtual micro bats is updated using following equations:

$$
\begin{aligned}
& f^{i}=f^{\min }+k\left(f^{\min }-f^{\max }\right) \\
& V^{i}{ }_{t+1}=V^{i}{ }_{t}+f^{i}\left(x_{t}^{i}-x^{s}\right) \\
& x_{t+1}^{i}=x_{t}^{i}+V^{i}{ }_{t}
\end{aligned}
$$

Where, $\mathrm{k}$ in the first expression is a random vector with uniform distribution. $\mathrm{x}^{\mathrm{S}}$ is the best available solution which is obtained with comparison between all the current positions of bats. When the best solution is selected among current solutions, each bat updates its position using following expression which is based on average loudness of all the bats $\left(\mathrm{A}^{\text {average }}\right)$ and we have:

$$
x^{\text {new }}=x^{\text {old }}+\alpha A^{\text {average }}
$$

Where, $\alpha$ is a random number between $[-1,1]$.

\section{Simulation Results}

The optimization is performed with using BAT algorithm was written for simulation of optimal location and size of DG in distribution systems according to weight factor of each function. The main purpose of this algorithm is showing any change in the function's weight in the multiobjective function leads to a significant change in the location and size of DG.

For this proposes, five different scenarios have been considered as follows:

\section{A. First scenario}

At the first scenario, coefficients have equal weight factors. Namely three functions such as loss reduction, improve voltage profile and DG fuel cost are equally important and we have:

$$
K_{1}=K_{2}=K_{3}=\frac{1}{3}
$$

In this case, the voltages drop of the bus-reaches to $0.95 \mathrm{pu}$ in worse case. Fig. 2 shows the voltage profile of the 13 bus network for the first scenario.

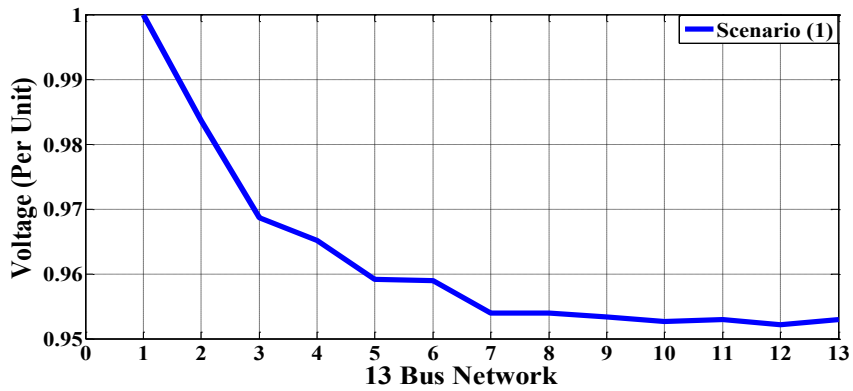

Fig. 2. Voltage profile of proposed network for first scenario

In the second scenario it is assumed that the weight factor of the DG fuel cost has a higher weight than losses and voltage profile. So, we have the following weight factors for the second scenario:

$K_{1}=K_{2}=0.2, K_{3}=0.6$

Fig. 3 shows the network voltage profile for the second scenario. As shown here, increasing the DG fuel cost factor increases the voltage drop as well.

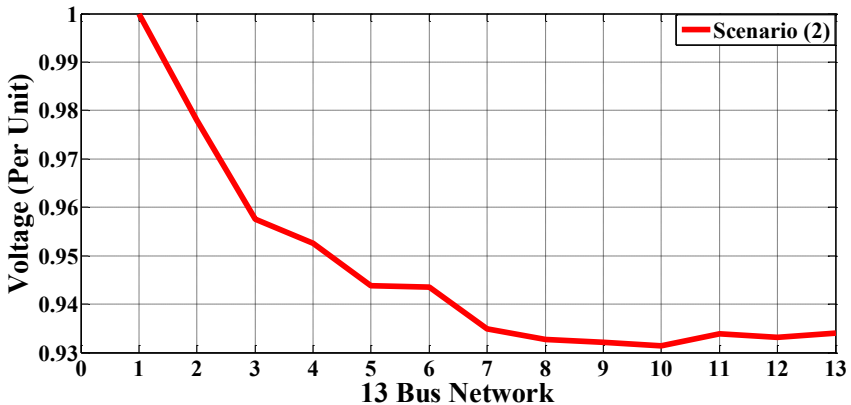

Fig. 3. Voltage profile of proposed network for second scenario

In the third scenario, it is assumed that the consumers distribution system has a high degree of importance, thereby improve function of voltage profile have a more importance and subsequently losses function is more important as well. In this case, the DG fuel costs have lower priority and we have the following weight factors:

$K_{1}=0.3, K_{2}=0.6, K_{3}=0.1$

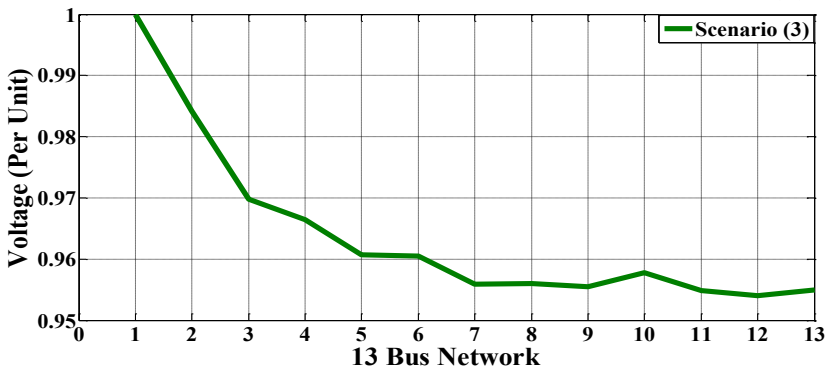

Fig. 4. Voltage profile of proposed network for third scenario 
Fig. 4 shows the customer voltage profile for this scenario. As shown in this figure, the voltage drop is improved considerable. In sever condition, the amplitude of the voltage profile reaches to $0.96 \mathrm{pu}$ which is acceptable voltage level for sensitive electrical loads. Fig. 5 shows fourth scenario where the DG fuel price factor has more value as compared with other two factors. The weight factor for this scenario is given as follows:

$\mathrm{K}_{1}=0.25, \mathrm{~K}_{2}=0.25, \mathrm{~K}_{3}=0.5$

The result of this scenario is like the result of scenario (2) and voltage profile has a dipper voltage drop up to $0.95 \mathrm{pu}$.

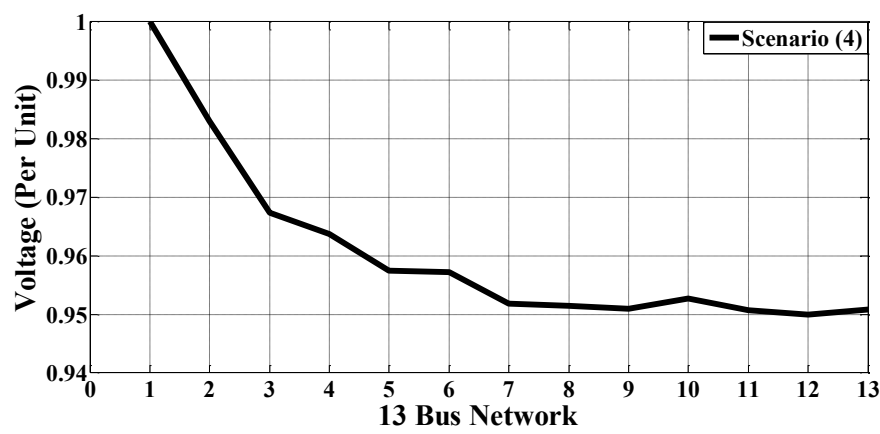

Fig. 5. Voltage profile of proposed network for fourth scenario

For the last scenario we have the following weight factors:

$K_{1}=0.05, K_{2}=0.45, K_{3}=0.5$

In this case, $\mathrm{K}_{3}$ is bigger than other two factors but the voltage drop has exceeded $0.95 \mathrm{pu}$ and its amplitude reaches to 0.94 pu as shown in Fig. 6.

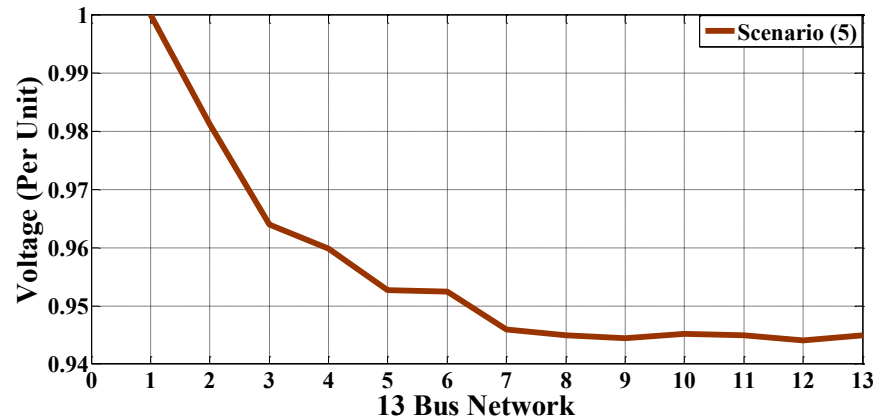

Fig. 6. Voltage profile of proposed network for fifth scenario

The proposed method has been developed in MATLAB software. The optimization algorithm in the paper is a BAT Optimization Algorithm. As mentioned before, a 13 busses distribution network is used to study the planning and placing capacity.

Table.3. Output of BAT algorithm

\begin{tabular}{|c|c|c|c|c|c|}
\hline Scenarios & $\begin{array}{c}\text { Bus } \\
\text { No.1 }\end{array}$ & $\begin{array}{c}\text { DG } \\
\text { Size.1 }\end{array}$ & $\begin{array}{c}\text { Loss } \\
\text { before } \\
\text { DG }\end{array}$ & $\begin{array}{c}\text { Loss } \\
\text { after } \\
\text { DG }\end{array}$ & $\begin{array}{c}\text { Loss } \\
\text { Reduction\% }\end{array}$ \\
\hline $\begin{array}{c}\text { Scenario } \\
1\end{array}$ & 8 & 4.52 & 291 & 154 & 46 \\
\hline $\begin{array}{c}\text { Scenario } \\
2\end{array}$ & - & - & - & - & - \\
\hline $\begin{array}{c}\text { Scenario } \\
3\end{array}$ & 10 & 5 & 291 & 147 & 49 \\
\hline Scenario & 10 & 4 & 291 & 152 & 47 \\
\hline
\end{tabular}

\begin{tabular}{|c|c|c|c|c|c|}
\hline 4 & & & & & \\
\hline $\begin{array}{c}\text { Scenario } \\
5\end{array}$ & 10 & 2.58 & 291 & 202 & 30 \\
\hline
\end{tabular}

Results of the BAT algorithm are listed in Table (3) for five set of scenarios. The results of the algorithm output show that increasing the weight factor of DG cost decreased the DG size. For example, row two of Table (3) shows that by increasing $K_{3}$ to 0.6 , DG size decreased to zero. In rows 2, 4 and 5, weight factor of the DG function is more important than other functions.

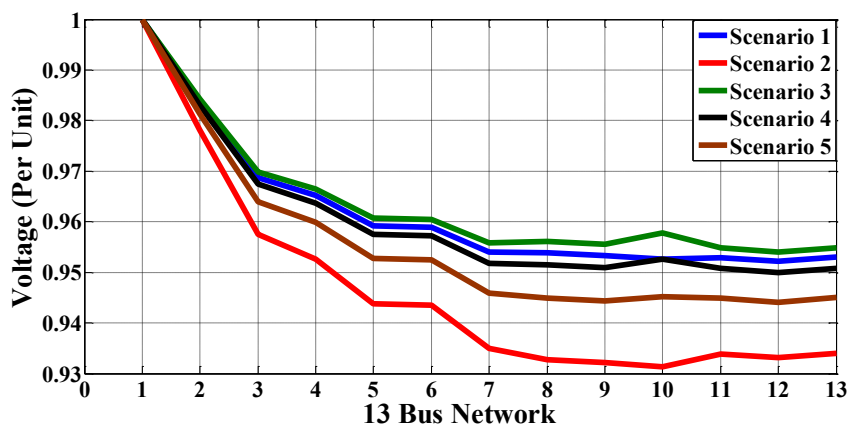

Fig. 7. Voltage profile in 13-bus network for different scenarios

For this purpose, DG generation is less than other rows. In Row 4, the coefficients $\mathrm{K}_{1}$ and $\mathrm{K}_{2}$ are equal to 0.25 but in row 5 these coefficients are $\mathrm{K}_{1}=0.05$ and $\mathrm{K}_{2}=0.45$. As seen in these rows, because of the weight factor of the losses function, losses in row 4 is more than row 5.

As shown in Fig. 7, because of voltage improvement function weight in row 5 is more than row 4, voltage profile has better condition. One of the results that determined in rows, by increased in function important $\left(\mathrm{K}_{3}\right)$, voltage profile is placed in a worse situation. One of the other results is losses function weight and improvement voltage has a positive interaction on the other.

\section{Conclusion}

In this paper, a proposed BAT algorithm is used to optimum the DG location at 13 bus distribution network. We studied the effects of the variation weight functions for determining location and size of DG and it was shown well according to various results. It was found that weight of losses functions and weight of improve voltage profile have influence on each other. On the other hand, improvement in one of them caused relative improve to another. But, the weight of third functions, i.e., DG fuel cost, will have a devastating influence on two other functions. Increasing the weight factor of these functions has a considerable effect on the DG optimum location as compared with other factor influence.

\section{References:}

[1] Sharifi, R., Anvari-Moghaddam, A., Fathi, S. H., Guerrero, J. M., \& Vahidinasab, V. (2019). An optimal market-oriented demand response model for priceresponsive residential consumers. Energy Efficiency, 12(3), 803-815.

[2] Lee, K.Y.; Xiaomin Bai; Young-Moon Park, "Optimization method for reactive power planning by using 
a modified simple genetic algorithm," IEEE Transactions on Power Systems, vol.10, no.4, pp.1843-1850, Nov. 1995.

[3] Ganjefar, S., et al. "Prediction of delay time in Internet by neural network." Proceedings of 2005 IEEE Conference on Control Applications, 2005. CCA 2005.. IEEE, 2005.

[4] Kalantari M, Sohrabi S, Rashidy Kanan H. A Hybrid Optimization Algorithm Based on Genetic Algorithm and Hyper Spherical Search Based on Chaos Theory. Journal of Iranian Association of Electrical and Electronics Engineers. 2019; 16 (3):147-155.

[5] Samaie F, Javadi S. Optimal Siting and Sizing of Hybrid Energy Systems (PV-WT-CHP) and Electric Vehicle Charging Stations Simultaneously based on Game Theory Approach. Journal of Iranian Association of Electrical and Electronics Engineers. 2019; 15 (4):123-135.

[6] Heidary Yazdi S S, Milimonfared J, Fathi S H. Unified Control Structure to Evaluate Grid Code Compatibility of HVDC Interfaced Offshore Wind Power Plant. Journal of Iranian Association of Electrical and Electronics Engineers. 2019; 16 (3) :87-100.

[7] Hedayati, H.; Nabaviniaki, S.A.; Akbarimajd, A., "A Method for Placement of DG Units in Distribution Networks," IEEE Transactions on Power Delivery, vol.23, no.3, pp.1620-1628, July 2008.

[8] Duong Quoc Hung; Mithulananthan, N.; Bansal, R.C., "Analytical Expressions for DG Allocation in Primary Distribution Networks," IEEE Transactions on Energy Conversion, vol.25, no.3, pp.814-820, Sept. 2010.

[9] Kamali, R., Sharifi, R., Radmanesh, H., \& Fathi, S. (2016). Online voltage estimation for distribution networks in presence of distributed generation. Indian Journal of Science and Technology, 9(18), 1-5.

[10] X. Hugang, C. Haozhong, L. Haiyu, "Optimal reactive power flow incorporating static voltage stability based on multi-objective adaptive immune algorithm", Energy conversion and management, vol. 49, pp. 1175-1181, May 2008.

[11] Singh, D.; Singh, D.; Verma, K.S., "Multiobjective Optimization for DG Planning with Load Models," IEEE Transactions on Power Systems, vol.24, no.1, pp.427-436, Feb. 2009.

[12] A. R. Phadke, M. Fozdar, K. R. Niazi, "A new multiobjective fuzzy-GA formulation for optimal placement and sizing of shunt FACTS controller", Electrical power and energy system, vol. 40, pp. 46-53, 2012.

[13] L. J. Cai, I. Erlich, G. Stamtsis, Optimal choice and allocation of FACTS devices in deregulated electricity market using genetic algorithm, Power systems conference and exposition, vol. 1, pp. 201-207, October 2004.

[14] M. Saravanan, S. Mary Raja Slochanal, P. Venkatesh, J. Prince Stephen Abraham, "Application of particle swarm optimization technique for optimal location of FACTS devices considering cost of installation and system laudability ", Electric power systems research, vol. 77, pp. $276-283,2007$.

[15] R. S. Alabri, Ehab F. El-Saadany, Yasser M. Atwa, Optimal placement and sizing method to improve the voltage stability margine in adistribution system using distributed generation, IEEE transactions on power system, vol. 28, pp. 326-334, February 2013.

[16] M. H. Moradi, M. Abedini, A combination of genetic algorithm and particle swarm optimization for optimal DG location and sizing in distribution systems, International journal of electrical power and energy systems, vol. 34, pp. 66-74, January 2012.

[17] Arulraj, R.; Kumarappan, N.; Vigneysh, T., "Optimal location and sizing of DG and capacitor in distribution network using Weight-Improved Particle Swarm Optimization Algorithm (WIPSO)," 2013 International Multi-Conference on Automation, Computing, Communication, Control and Compressed Sensing (iMac4s), vol., no., pp.759-764, 22-23 March 2013.

[18] Niknam, T.; Azizipanah-Abarghooee, R.; Zare, M.; Bahmani-Firouzi, B., "Reserve Constrained Dynamic Environmental/Economic Dispatch: A New Multiobjective Self-Adaptive Learning Bat Algorithm," IEEE Systems Journal, vol.7, no.4, pp.763-776, Dec. 2013.

[19] Bora, T.C.; Coelho, L.D.S.; Lebensztajn, L., "BatInspired Optimization Approach for the Brushless DC Wheel Motor Problem," IEEE Transactions on Magnetics, vol.48, no.2, pp.947-950, Feb. 2012.

[20] Rashidi, F.; Abiri, E.; Niknam, T.; Salehi, M.R., "Online parameter identification of power plant characteristics based on phasor measurement unit recorded data using differential evolution and bat inspired algorithm," IET Science, Measurement \& Technology, vol.9, no.3, pp.376392, 52015.

[21] Nien-Che Yang; Minh-Duy Le, "Multi-objective bat algorithm with time-varying inertia weights for optimal design of passive power filters set," IET Generation, Transmission \& Distribution, vol.9, no.7, pp.644-654, 430 2015.

[22] Radmanesh H, Radmanesh A. Pilot smart helmet with monitoring and transferring vital data with high-speed control Inspired by Dynamixel technology. Journal of Iranian Association of Electrical and Electronics Engineers. 2020; 17 (3) :79-91.

[23] Mokhtarpour, A.; Bathaee, M.; Shayanfar, H.A., "Power quality compensation in smart grids with a single phase UPQC-DG," 2012 2nd Iranian Conference on Smart Grids (ICSG), vol., no., pp.1-5, 24-25 May 2012.

[24] Kayal, P.; Ashish, T.; Chanda, C.K., "Simultaneou placement and sizing of renewable DGs and capacitor banks in distribution network," 2014 International Conference on Circuit, Power and Computing Technologies (ICCPCT), vol., no., pp.607-611, 20-21 March 2014.

[25] Juanuwattanakul, M. A. S. Masoum, Increasing distributed generation penetration in multiphase distribution networks considering grid losses, maximum loading factor and bus voltage limits, IET generation and distribution, vol 6, pp. 1262-1271, December 2012.

[26] R. Baghipour, S. M. Hosseini, "Placement of DG and capacitor for loss reduction, reliability and voltage improvement in distribution networks using BPSO", I. J intelligent systems and applications, vol. 12, pp. 57-64 2012. 